\title{
Return to sports after arthroscopic debridement and bone marrow stimulation of osteochondral talar defects: a 5- to 24-year follow-up study
}

\author{
I. C. M. van Eekeren ${ }^{1}$ C. J. A. van Bergen ${ }^{1}$ I. N. Sierevelt ${ }^{2}$ M. L. Reilingh ${ }^{1}$ • \\ C. N. van Dijk ${ }^{1}$
}

Received: 14 September 2015 / Accepted: 12 January 2016 / Published online: 4 February 2016

(c) The Author(s) 2016. This article is published with open access at Springerlink.com

\begin{abstract}
Purpose Osteochondral defects (OCD) often have a severe impact on the quality of life due to deep ankle pain during and after weight bearing, which prevents young patients from leading an active life. Arthroscopic debridement and bone marrow stimulation are currently the gold standard treatment. The purpose of this study was to evaluate the number of patients that resume and maintain sports to their pre-injury activity level after arthroscopic debridement and bone marrow stimulation.

Methods This retrospective study evaluated patients treated with arthroscopic debridement and bone marrow stimulation between 1989 and 2008. All patients who were participating in sports before injury were included. The Ankle Activity Scale (AAS) was used to determine activity levels during specific time points (before injury, before operation, after operation and at the time of final follow-up).

Results Ninety-three patients were included. Fifty-seven (76\%) patients continued participating in sports at final follow-up. The median AAS before injury of 8 (range 3-10) significantly decreased to 4 (range 2-10) at final follow-up. Conclusion It is shown that $76 \%$ of the patients were able to return to sports at long-term follow-up after arthroscopic debridement and bone marrow stimulation of talar OCDs. The activity level decreased at long-term follow-up
\end{abstract}

I. C. M. van Eekeren

i.c.vaneekeren@amc.uva.nl

1 Department of Orthopaedic Surgery, Academic Medical Centre, University of Amsterdam, PO Box 22660, 1100 DD Amsterdam, The Netherlands

2 Department of Orthopaedic Surgery, Slotervaart Ziekenhuis, Amsterdam, The Netherlands and never reached the level of that before injury. The data of our study can be of importance to inform future patients on expectations after debridement and bone marrow stimulation of a talar OCD.

Level of evidence Retrospective case series, Level IV.

Keywords Osteochondral defect $\cdot$ Arthroscopic debridement and bone marrow stimulation $\cdot$ Sports resumption $\cdot$ Long-term follow-up

\section{Introduction}

Osteochondral talar defects (OCDs) are common after an ankle distortion [20]. Approximately $50 \%$ of ankle sprains and fractures are associated with an OCD [10, 16]. OCDs can have a severe impact on the quality of life due to deep ankle pain during and after weight bearing [17]. If these defects are left untreated, patients are unable to live an active life $[8,20]$. Surgical treatment is indicated when primary non-operative treatment fails or is insufficient [13]. The primary surgical treatment for OCDs up to $15 \mathrm{~mm}$ consists of arthroscopic debridement and bone marrow stimulation with an overall success rate of $85 \%$, lasting over the years to have a $76 \%$ satisfactory outcome at long term $[14,15,19]$. Success rate is related to pain levels and the ability to perform the activities of daily life; however, these do not take into account the sport activity level of patients. For athletes with an OCD, the lapse before resuming highimpact sport after surgery can be as much as 3-6 months $[2,5,10]$. Recently, a prospective study showed that $80 \%$ of the patients return to their pre-injured sport level within 1 year after arthroscopic debridement and microfracturing of an OCD of the talus [7]. However, little is known about the long-term follow-up of this treatment. The hypothesis 
was that patients were able to continue sports activity after debridement and bone marrow stimulation in the long term.

The purpose of this study was to evaluate: (1) the proportion of patients that return to sports after arthroscopic debridement and bone marrow stimulation of OCDs at long-term follow-up, and (2) the activity level before injury, before surgery and at long-term follow-up.

\section{Materials and methods}

In a retrospective study, questionnaires were used to evaluate patients treated at our department with arthroscopic debridement and bone marrow stimulation of an OCD of the talus between March 1989 and December 2008. All patients who participated in sports before injury were included. The exclusion criterion was a concomitant OCD of the tibial plafond.

The Ankle Activity Scale (AAS) by Halasi et al. was used to determine sporting and activity levels at specific time points (before injury, before operation, after operation and at the time of final follow-up). The AAS is a single-page survey system that contains 53 sports, 3 working activities and 4 general activities. Zero points indicate the lowest activity and 10 points indicate the highest activity [3]. The AAS is a specific tool to evaluate sports activity for the ankle joint based on the Tegner score. Reliability for the AAS is not yet reported; however, reliability of the Tegner score for knee-specific injuries is accepted [1].

Secondary outcomes were clinical history, body mass index (BMI), numeric rating scale (NRS) and Foot and Ankle Outcome Score (FAOS) [9, 12, 18]. The reliability for the FAOS is accepted with an ICC of the subscales ranging from 0.83 to 0.88 and a small detective change of 2.1 and 2.5 [12]. Furthermore, patients rated their overall satisfaction with the operation $(1=$ poor, $2=$ average, $3=$ fair, $4=\operatorname{good}, 5=$ excellent) and indicated whether the complaints had changed since the operation $(0=$ extremely deteriorated, $1=$ significantly deteriorated, $2=$ some deteriorated, $3=$ unchanged, $4=$ little improved, $5=$ significantly improved, $6=$ completely restored).

In accordance with the ethical standards as were laid down in the 1964 Declaration of Helsinki, approval of an ethics committee for the questionnaires was not required, as confirmed by the ethics committee of our institution (Amsterdam Medical Centre; reference number W15-251\#15.0296).

\section{Statistical analysis}

SPSS statistics 22 (Chicago, IL) was used for statistical analysis. Descriptive statistics of continuous variables were calculated as means \pm standard deviations or median

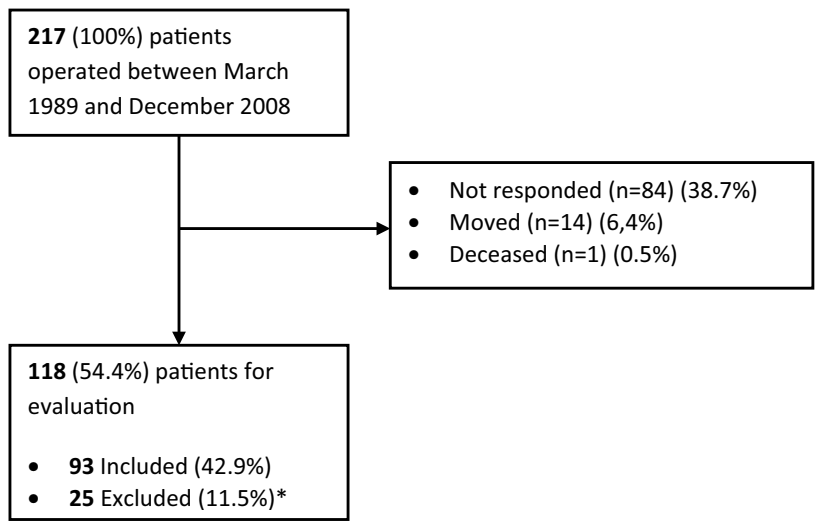

Fig. 1 Flowchart. Asterisk Twenty-five patients excluded for not participating in sports before injury

and ranges in case of a skewed distribution. Categorical variables were presented as frequencies with percentages. Due to skewed distributions and ordinal character of the outcome variables, analysis was performed nonparametrically. Continuous outcome variables (AAS, NRS, FAOS) and categorical baseline variables (sex, side, location and primary of secondary defect) were assessed using MannWhitney $U$ tests or Kruskal-Wallis tests where appropriate. For continuous baseline values, Spearman's rho was calculated (age at time of surgery and present and BMI). Overall significance of the AAS between different time moments was checked by use of the Friedman's test. In case of significance, post hoc pairwise comparison of the AAS several time points was performed by use of Wilcoxon signedrank test. Sports activity was compared at different time points by use of McNemar tests. To compare patients with a longer follow-up to a shorter follow-up, the group was divided into four different follow-up groups (5-9, 10-14, 15-19 and 20-24 years). The level of significance was set at $P<0.05$.

\section{Results}

During the study period, 217 patients were available for evaluation of which 118 patients $(54.4 \%)$ responded. Twenty-five patients were excluded because they were not participating in sports before injury. Therefore, 93 patients $(42.9 \%)$ were evaluated (Fig. 1). The median post-operative follow-up was 118 months (range 46-271; Table 1). Patient's demographics are displayed in Table 1.

Of all $93(100 \%)$ patients that participated in sports before injury, $57(61 \%)$ patients participated in a sport before the operation, $72(77 \%)$ after the operation and $71(76 \%)$ at the time of final follow-up (Table 2). Significantly fewer patients participated in sports before the 
operation, after operation and at the time of final followup, as compared to pre-injury $(P<0.01)$. The median AAS before injury was 8 (range $3-10$ ), before operation it was 5 (range 2-9), after operation, it was 5 (1-10), and the AAS at time of final follow-up was 4 (2-10). The AAS was significantly higher before injury compared to the other three time points $(P<0.01)$. The AAS did not differ between the different follow-up groups. Moreover, no significant differences were observed in the AAS between follow-up groups

Table 1 Patient demographics

\begin{tabular}{lc}
\hline Age at time of surgery, mean (SD) & $32.6(9.5)$ \\
Age at present, mean (SD) & $43.8(10.7)$ \\
Follow-up (months), median (range) & $118(46-271)$ \\
Sex, $n(\%)$ & \\
Male & $61(66 \%)$ \\
Female & $32(34 \%)$ \\
BMI at time of surgery, mean (SD) & $25.5(3.0)$ \\
Side, $n(\%)$ & \\
Right & $55(60 \%)$ \\
Left & $38(40 \%)$ \\
Location, $n(\%)$ & \\
Medial & $63(68 \%)$ \\
Lateral & $26(28 \%)$ \\
Unknown & $4(4 \%)$ \\
Defect, $n(\%)$ & \\
Primary & $68(73 \%)$ \\
Secondary & $25(27 \%)$ \\
\hline
\end{tabular}

at final follow-up. Baseline variables were not significantly associated with the AAS at any time point.

The type of sports often changed during follow-up, as compared to before injury (Table 3 ). At the time of final follow-up, more patients participated in low-impact sports such as cycling and swimming than before injury.

In our population, achievement of overall satisfaction with the operation was reported to be $65 \%$ and improvement of symptoms more than $73 \%$ (Table 4). The median NRS for pain at rest was 1 (range 0-8), that for pain when walking was 2 (range 0-9) and the NRS for pain during running was 4 (range $0-10$ ). The subscale quality of life of the FAOS with a median of 56.3 (range 0-100) was the lowest subscale and with a median of 100 (range 99-100) was ADL highest subscale (Table 4). Seventy-five per cent of the patients $(n=70)$ did not have a re-operation, while $4 \%(n=4)$ had another arthroscopy for the OCD, one patient (1\%) had an ankle fusion, and $13 \%$ had a hyaluronic acid injection $(n=12)$. Baseline variables were not significantly associated with the secondary outcomes.

\section{Discussion}

Seventy-six per cent of the patients continuing participating in sports at long-term follow-up after arthroscopic debridement and bone marrow stimulation of OCD of the talus were the most important finding of our study. However, the activity level decreased and never reached the level of that before injury. No differences were found when comparing

Table 2 Number of patients participating in sports and their activity level (AAS)

\begin{tabular}{|c|c|c|c|c|c|c|c|c|c|c|}
\hline & \multicolumn{8}{|l|}{ Follow-up } & \multicolumn{2}{|l|}{ Total } \\
\hline & \multicolumn{2}{|c|}{$5-9$ years $(n=42)$} & \multicolumn{2}{|c|}{$10-14$ years $(n=34)$} & \multicolumn{2}{|c|}{$15-19$ years $(n=13)$} & \multicolumn{2}{|c|}{$20-24$ years $(n=4)$} & \multirow[b]{2}{*}{$\begin{array}{l}\text { Sports } \\
\text { participation } \\
(\%)\end{array}$} & \multirow[b]{2}{*}{ AAS } \\
\hline & $\begin{array}{l}\text { Sports } \\
\text { participation } \\
(\%)\end{array}$ & AAS & $\begin{array}{l}\text { Sports } \\
\text { participation } \\
(\%)\end{array}$ & AAS & $\begin{array}{l}\text { Sports } \\
\text { participation } \\
(\%)\end{array}$ & AAS & $\begin{array}{l}\text { Sports } \\
\text { participation } \\
(\%)\end{array}$ & AAS & & \\
\hline $\begin{array}{l}\text { Before } \\
\text { injury }\end{array}$ & 100 & $9(3-10)$ & 100 & $8(3-10)$ & 100 & $9(4-9)$ & 100 & $7.5(7-9)$ & 100 & $8(3-10)$ \\
\hline $\begin{array}{l}\text { Before } \\
\text { operation }\end{array}$ & $62 *$ & $5(1-10)^{*}$ & $65^{*}$ & $6(1-10)^{*}$ & 62 & $4(1-10)^{*}$ & 50 & $1(1-7)$ & $61^{*}$ & $5(2-9)^{*}$ \\
\hline $\begin{array}{l}\text { After opera- } \\
\text { tion }\end{array}$ & $67 *$ & $5(2-10)^{*}$ & $88^{\dagger}$ & $5(2-9)^{*}$ & 92 & $6(2-10)^{*}$ & 50 & $4(2-8)$ & $77^{*}$ & $5(1-10)^{*}$ \\
\hline $\begin{array}{l}\text { At the time } \\
\text { of final } \\
\text { follow-up }\end{array}$ & $67 *$ & $5(2-9)^{*}$ & $91^{\dagger}$ & $5(2-9)^{*}$ & $77 \%$ & $4(2-7)^{*}$ & 50 & $4(2-7)$ & $76^{*}$ & $4(2-10)^{* *}$ \\
\hline$P$ value & & n.s. & & $P=0.01$ & & $P=0.01$ & & n.s. & & $P=0.00$ \\
\hline
\end{tabular}

$A A S$ Ankle Activity Scale, given in median with ranges

$* P<0.05$ compared to before injury level; ${ }^{\dagger} P<0.05$ compared to before operation; ${ }^{\sharp} P<0.05$ compared to after operation. Overall significance assessed with Friedman's tests. In case of significance, post hoc pairwise comparison was assessed with the Wilcoxon signed-rank test (for AAS) or by use of McNemar tests (sports participation) 
Table 3 Sports participation at different time points

\begin{tabular}{|c|c|c|c|c|}
\hline Sport & Before injury (\%) & Before operation (\%) & After operation (\%) & At the time of final follow-up (\%) \\
\hline Soccer & 45 & 35 & 24 & 13 \\
\hline Tennis & 22 & 18 & 15 & 13 \\
\hline Cycling & 12 & 11 & 21 & 30 \\
\hline Running & 11 & 11 & 11 & 18 \\
\hline Downhill skiing & 10 & 0 & 9 & 8 \\
\hline Fitness & 9 & 9 & 24 & 27 \\
\hline Squash & 8 & 9 & 1 & 0 \\
\hline Gymnastics & 6 & 2 & 1 & 0 \\
\hline Basketball & 6 & 4 & 4 & 3 \\
\hline Swimming & 6 & 7 & 6 & 9 \\
\hline Athletics & 5 & 7 & 4 & 0 \\
\hline Aerobics & 4 & 4 & 0 & 1 \\
\hline Volleyball & 5 & 4 & 3 & 3 \\
\hline Triathlon & 3 & 4 & 0 & 0 \\
\hline Ice skating & 3 & 4 & 1 & 3 \\
\hline
\end{tabular}

Table 4 Secondary outcome measures

\begin{tabular}{lclclc}
\hline FAOS, median (range) & \multicolumn{2}{l}{ Satisfaction, $n(\%)$} & \multicolumn{2}{l}{ Change in complaints, $n(\%)$} \\
\hline Symptoms & $64.3(14-100)$ & Excellent & $18(20 \%)$ & Completely restored & $11(12 \%)$ \\
Pain & $77.8(25-100)$ & Good & $42(45 \%)$ & Significantly improved & $39(42 \%)$ \\
ADL & $100(99-100)$ & Fair & $19(20 \%)$ & Little improved & $16(17 \%)$ \\
Sport & $65(0-100)$ & Average & $9(10 \%)$ & Unchanged & $13(14 \%)$ \\
QOL & $56.3(0-100)$ & Poor & $4(4 \%)$ & Some deteriorated & $5(5 \%)$ \\
& & & & Significantly deteriorated & $5(5 \%)$ \\
& & & & Extremely deteriorated & $1(1 \%)$ \\
\hline
\end{tabular}

different follow-up groups regarding the number of patients participating in sports and the activity level.

Comparing to the existing literature, Saxena and Eakin found a return to activity (high demand) rate of $95 \%$ in approximately 17 weeks after surgery. They prospectively followed 44 patients that were divided into bone grafting and microfracturing (combined arthroscopically and open by medial malleolar osteotomy) with an average follow-up of 32 months [10].

Seijas et al. [11] treated 16 professional soccer players with an osteochondral talar defect by means of arthroscopic microfracturing. Their athletes returned to sporting activity in approximately 20 weeks, and more than $90 \%$ of the patients were able to resume to their former sporting level after an average of 3.5 years.

Lee et al. prospectively followed 35 patients with a mean follow-up of almost 3 years (33 months). Before operation, 18 patients were actively involved in sporting activities of different intensities (basketball, baseball, tennis, wrestling), while the other 17 were interested at recreational level of sports. At follow-up, $63 \%$ of the patient achieved their preinjury sports level which is comparable to the results in our study [4]. The resumption of sports is lower in our study compared to the literature mentioned above. We included, however, not only athletes, but all patients participating in sports before injury. We thereby defined the activity level of patients with a validated activity level score (AAS) and were able to compare the score before injury to final follow-up.

Compared with patients treated with osteochondral transplantation, the results of our study are comparable. Paul et al. showed, however, in a retrospective design a decrease of only $8 \%$ in the number of patients sporting compared to lifetime sports. Comparable to our study, the intensity of sports decreased as well measured in activity scales such as the Tegner and activity rating scale. They also noticed a change of sports towards lower-impact sports, such as cycling and swimming, which we observed as well [6].

Although not prospectively designed, it is shown to be the largest group of patients with the longest follow-up investigating the return to sports after arthroscopic debridement and bone marrow stimulation of talar OCDs. Besides, our study included patients that were participating in sports at any level and not only professional athletes. 
The retrospective design, recall bias and low response rate were identified as limitations of our study. Because of the retrospective design, it was not possible to compare the secondary outcome to pre-operative data and have no information over the specific time to return to sports. The longterm follow-up allowed us to compare different follow-up groups and showed that the AAS as well as the number of patients that resumed sports did not deteriorate over time. Another limitation is the recall bias of the patients, which can influence the results of our study. Thereby, the study had a relatively low response rate. Possible selection bias could affect the study. Amongst the 217 patients operated in the study period were patients participating in sports as well as patients not participating in sports before injury. Before sending the questionnaire and inclusion of the patients, this was not distinguished. Therefore, the response rate stated in this study will probably be underreported.

\section{Conclusion}

It is shown that $76 \%$ of the patients were able to return to sports at long-term follow-up after arthroscopic debridement and bone marrow stimulation of talar OCDs. However, the activity level decreased at long-term follow-up and never reached the level of that before injury. No differences were found when comparing different follow-up groups regarding the number of patients participating in sports and the activity level. The top cited sports did not change; however, we noticed a modification towards lowerimpact sports. The data of our study can be important to inform future patients on expectations after debridement and bone marrow stimulation of a talar OCD.

Open Access This article is distributed under the terms of the Creative Commons Attribution 4.0 International License (http://creativecommons.org/licenses/by/4.0/), which permits unrestricted use, distribution, and reproduction in any medium, provided you give appropriate credit to the original author(s) and the source, provide a link to the Creative Commons license, and indicate if changes were made.

\section{References}

1. Briggs KK, Lysholm J, Tegner Y, Rodkey WG, Kocher MS, Steadman JR (2009) The reliability, validity, and responsiveness of the Lysholm score and Tegner activity scale for anterior cruciate ligament injuries of the knee: 25 years later. Am J Sports Med 37:890-897

2. Cerynik DL, Lewullis GE, Joves BC, Palmer MP, Tom JA (2009) Outcomes of microfracture in professional basketball players. Knee Surg Sports Traumatol Arthrosc 17:1135-1139
3. Halasi T, Kynsburg A, Tallay A, Berkes I (2004) Development of a new activity score for the evaluation of ankle instability. Am J Sports Med 32:899-908

4. Lee KB, Bai LB, Chung JY, Seon JK (2010) Arthroscopic microfracture for osteochondral lesions of the talus. Knee Surg Sports Traumatol Arthrosc 18:247-253

5. Mithoefer K, Williams RJ III, Warren RF, Wickiewicz TL, Marx RG (2006) High-impact athletics after knee articular cartilage repair: a prospective evaluation of the microfracture technique. Am J Sports Med 34:1413-1418

6. Paul J, Sagstetter M, Lammle L, Spang J, El-Azab H, Imhoff AB, Hinterwimmer S (2012) Sports activity after osteochondral transplantation of the talus. Am J Sports Med 40:870-874

7. Reilingh ML, van Bergen CJA, Gerards RM et al (2015) Effects of pulsed electromagnetic fields on return to sports after arthroscopic debridement and microfracturing of osteochondral talar defects: a randomized, double-blind, placebo-controlled, multicenter trial. Am J Sports Med.doi:10.1177/0363546515626544

8. Robinson DE, Winson IG, Harries WJ, Kelly AJ (2003) Arthroscopic treatment of osteochondral lesions of the talus. J Bone Jt Surg Br 85:989-993

9. Roos EM, Brandsson S, Karlsson J (2001) Validation of the foot and ankle outcome score for ankle ligament reconstruction. Foot Ankle Int 22:788-794

10. Saxena A, Eakin C (2007) Articular talar injuries in athletes: results of microfracture and autogenous bone graft. Am J Sports Med 35:1680-1687

11. Seijas R, Alvarez P, Ares O, Steinbacher G, Cusco X, Cugat R (2010) Osteocartilaginous lesions of the talus in soccer players. Arch Orthop Trauma Surg 130:329-333

12. Sierevelt IN, Beimers L, van Bergen CJ, Haverkamp D, Terwee CB, Kerkhoffs GM (2015) Validation of the Dutch language version of the foot and ankle outcome score. Knee Surg Sports Traumatol Arthrosc 23:2413-2419

13. van Bergen CJ, de Leeuw PA, van Dijk CN (2008) Treatment of osteochondral defects of the talus. Rev Chir Orthop Reparatrice Appar Mot 94:398-408

14. van Bergen CJ, Kox LS, Maas M, Sierevelt IN, Kerkhoffs GM, van Dijk CN (2013) Arthroscopic treatment of osteochondral defects of the talus: outcomes at eight to twenty years of followup. J Bone Jt Surg Am 95:519-525

15. van Dijk CN (2014) Ankle arthroscopy: techniques developed by the Amsterdam Foot and Ankle School, vol 1. Springer, Berlin, pp 149-186

16. van Dijk CN, Bossuyt PM, Marti RK (1996) Medial ankle pain after lateral ligament rupture. J Bone Jt Surg Br 78:562-567

17. van Dijk CN, Reilingh ML, Zengerink M, van Bergen CJ (2010) Osteochondral defects in the ankle: why painful? Knee Surg Sports Traumatol Arthrosc 18:570-580

18. Weel H, Zwiers R, Sierevelt IN, Haverkamp D, van Dijk CN, Kerkhoffs GM (2015) Dutch-language patient-reported outcome measures for foot and ankle injuries; a systematic review. Ned Tijdschr Geneeskd 159:A8831

19. Zengerink M, Struijs PA, Tol JL, van Dijk CN (2010) Treatment of osteochondral lesions of the talus: a systematic review. Knee Surg Sports Traumatol Arthrosc 18:238-246

20. Zengerink M, Szerb I, Hangody L, Dopirak RM, Ferkel RD, van Dijk CN (2006) Current concepts: treatment of osteochondral ankle defects. Foot Ankle Clin 11:331-359 